\title{
inu \\ On the Potential of Using Air Pressure Fluctuations to Estimate Wind-Induced Tree Motion in a Planted Scots Pine Forest
}

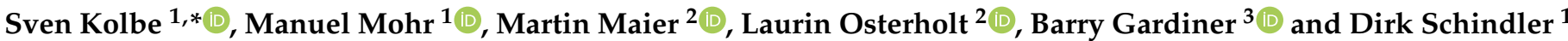 \\ 1 Chair of Environmental Meteorology, Albert-Ludwigs-University of Freiburg, Werthmannstrasse 10, \\ 79085 Freiburg, Germany; manuel.mohr@meteo.uni-freiburg.de (M.M.); \\ dirk.schindler@meteo.uni-freiburg.de (D.S.) \\ 2 Forest Research Institute Baden-Wuerttemberg, Wonnhaldestrasse 9, 79100 Freiburg, Germany; \\ martin.maier@forst.bwl.de (M.M.); laurin.osterholt@forst.bwl.de (L.O.) \\ 3 Chair of Forestry Economics and Forest Planning, Albert-Ludwigs-University of Freiburg, Tennenbacher \\ Strasse 4, 79106 Freiburg, Germany; barry.gardiner@ife.uni-freiburg.de \\ * Correspondence: sven.kolbe@meteo.uni-freiburg.de; Tel.: +49-761-203-3588
}

Citation: Kolbe, S.; Mohr, M.; Maier, M.; Osterholt, L.; Gardiner, B.; Schindler, D. On the Potential of Using Air Pressure Fluctuations to Estimate Wind-Induced Tree Motion in a Planted Scots Pine Forest. Forests 2022, 13, 225. https://doi.org/ $10.3390 /$ f13020225

Academic Editor: Roger Seco

Received: 15 December 2021

Accepted: 25 January 2022

Published: 2 February 2022

Publisher's Note: MDPI stays neutral with regard to jurisdictional claims in published maps and institutional affiliations.

Copyright: (C) 2022 by the authors. Licensee MDPI, Basel, Switzerland. This article is an open access article distributed under the terms and conditions of the Creative Commons Attribution (CC BY) license (https:// creativecommons.org/licenses/by/ $4.0 /)$.

\begin{abstract}
This paper reports statistical relationships between measured airflow, air pressure fluctuations, and the wind-induced motion of planted Scots pine trees (Pinus sylvestris L.). The results presented illustrate the potential of low-cost, ground-based air pressure measurements for monitoring wind-induced tree response. It is suggested that air pressure fluctuations can be used as surrogate information for above-canopy airflow, often used to estimate wind loads on forest trees. We demonstrate that air pressure fluctuations can be measured representatively at the forest floor and correlate very well with wind speed and direction at mean canopy-top (18 $\mathrm{m}$ a.g.l.) and above the $18 \mathrm{~m}$ high, 56-year-old forest. Their strong correlation (coefficient of determination $R^{2}>0.77$ ) allows a good approximation of airflow conditions above the canopy, and, with some limitations, in the below-canopy space. Air pressure fluctuations also correlate very well with wind-induced tree motion with a similar correlation to that between wind speed and tree motion. Furthermore, the main directions of wind-induced tree motion agree very well with the propagation direction of air pressure waves. Above-canopy airflow measurements in forests with a large vertical extent are rare, and often require tall wind measurement towers. Therefore, we consider the estimation of airflow conditions over forests using ground-based air pressure measurements a promising option for monitoring the airflow conditions of relevance for predicting wind-induced tree response over large areas using a minimum of measurement infrastructure.
\end{abstract}

Keywords: air pressure sensor network; tree response; storm hazard; Hartheim forest

\section{Introduction}

The characteristics of near-ground wind fields are important physical site factors that contribute to the development and survival of trees and forests [1,2]. Local wind fields affect trees' physiological, morphological, and biomechanical adaptations to their atmospheric environment [2-6]. However, information on above- and below-canopy wind characteristics is limited because the standard weather stations operated in the networks of the national weather services are located outside forests. Within stand wind characteristics are mainly known from specialized sites of forest research institutes [7,8], research networks such as the European Integrated Carbon Observation System [9], and the International Cooperative Programme on Assessment and Monitoring of Air pollution Effects on Forests [10]. Otherwise, little systematic information and data are available on the wind fields in and over forests.

The reasons for the lack of wind measurement sites in forests are the great effort required to make such measurements, the lack of infrastructure, and the low spatial representativeness of below-canopy measurements. Due to large vertical extent of forests, it is 
often not sufficient for many scientific questions to just measure wind speed and direction at the standard height set at $10 \mathrm{~m}$ by the World Meteorological Organization [11]. In most cases, the assessment of wind characteristics requires the installation of tall measuring towers carrying multiple anemometers up to heights greater than the mean forest stand height to fully represent the influence of forests on the vertical wind profiles.

One field in which knowledge of local wind conditions is essential is the wind excitation of tree motion [12,13]. It spans many temporal and spatial scales because the wind's kinetic energy is transferred to all aerial tree parts [14]. Based on the duration and intensity of local wind loading on trees, a distinction is made between chronic and acute wind loading. Chronic wind loading is defined as the long-term effect of continuous, non-destructive wind action on trees that causes adaptations to site-specific airflow conditions $[4,6,13]$. Obvious morphological adaptations of trees include reduction in height growth [15], increase in radial growth [6,16], and tree crown deformations [17]. Biomechanical adaptations modify wood properties such as the modulus of elasticity [18-20] that are probably adaptations to make the wood more pliable and able to absorb more bending energy under wind loading.

Aerial tree parts respond to different airflow characteristics. The total response to wind excitation is a tree-specific combination of quasi-static and dynamic interactions with effective wind loads [2,21]. The effective wind loads can be determined by separating non-turbulent from turbulent airflow parts measured at the canopy top or above the canopy $[22,23]$. This separation can be achieved through the simple approach of Reynolds averaging [24], i.e., splitting airflow variables into mean and fluctuating parts. This simple separation can investigate relationships between mean and turbulent wind loads and quasistatic and dynamic tree reactions, respectively. Reynolds averaging is particularly useful for long-term monitoring of trees for their response to endemic wind climate characteristics, e.g., growth and failure potential studies in trees and forests.

Unfortunately, high-quality long-term monitoring of the local wind climate in forests is challenging and often cannot be maintained at the same quality and configuration for a long time due to forest growth and limited resources. Therefore, alternative methods for monitoring wind conditions in and over forests are desirable. One possibility is to utilize small $(-20$ to $20 \mathrm{~Pa})$ air pressure fluctuations at the forest floor $[25,26]$.

Small fluctuations of air pressure can result from turbulence induced by the interaction of airflow with forest [27,28] and terrain [29]. For example, airflow over vegetation canopies leads to a shear instability at the canopy top that generates turbulence [30,31]. In turbulent airflow, periodic, coherent structures can be observed that are responsible for efficient heat and momentum transport in the vegetation-atmosphere interface [32,33]. Another study argues that the below-canopy air pressure pattern is closely linked with coherent structures [34]. Therefore, it is reasonable to assume that coherent structures are also responsible for within-canopy air pressure fluctuations.

Although this local concept of air pressure fluctuations' origin is very plausible, until now, the source of wind-induced, below-canopy air pressure fluctuations is under debate. Earlier studies tried to narrow down the origin of the small wind-induced air pressure fluctuations but have not yet come to any conclusive results $[25,26,35]$. No deterministic relationships could be established between below-canopy air pressure fluctuations and wind speed, horizontal and vertical wind vector components, momentum flux or air temperature associated with coherent structures [25]. Although the source of the small air pressure fluctuations is still debated, they can be correlated to local wind characteristics $[36,37]$. This correlation was used in previous studies to calculate the pressure pumping coefficient $(P P C)$, which describes the strength of the pressure pumping, i.e., the difference in amplitude between subsequent pressure fluctuations having an influence on gas transport in porous media [38-42].

To assess the strength of pressure pumping in a Norway spruce forest (Picea abies L.), the variation of above-canopy wind speed was found to be most appropriate [43]. Similar results were reported for a planted Scots pine (Pinus sylvestris L.) forest [25], where 
a link between the strength of pressure pumping and the mean above-canopy wind speed was determined. A subsequent study at the same forest site showed that the propagation direction and speed of air pressure fluctuations are also strongly correlated with the abovecanopy wind speed and direction [35].

Since strong functional relationships can be established between wind conditions over forests and small, wind-induced air pressure fluctuations measured near the ground, an alternative to tower-based wind speed and direction measurements in forests is presented in this paper. The proposed method allows the assessment and monitoring of tree reaction to local mean and turbulent airflow. For this, we first assess the functional relationship between the above-canopy wind speed and air pressure fluctuations measured near the ground in a planted Scots pine forest. Then, the air pressure fluctuations were directly related to the wind-induced tree motion. It is shown that the method is suitable for monitoring the means and extremes of the response of forest trees to the wind in situations where no above-canopy wind speed and direction measurements are available.

\section{Methods}

\subsection{Study Site}

Airflow, air pressure, and tree motion measurements (sampling frequency $10 \mathrm{~Hz}$ ) were conducted from 3 to 28 July 2020 at the Hartheim forest research site operated by Environmental Meteorology of the University of Freiburg, Germany [44]. The research site is located in a planted Scots pine forest established in 1964, in the flat, north-south aligned southern Upper Rhine valley $\left(47^{\circ} 56^{\prime} 04^{\prime \prime} \mathrm{N}, 7^{\circ} 36^{\prime} 02^{\prime \prime} \mathrm{E}, 201 \mathrm{~m}\right.$ a.s.l.) on the border of Germany with France. During the measurement period, the stand density was 550 trees per hectare, the mean stand height was $18.0 \mathrm{~m}$, and the mean plant area index of the sparse canopy was 1.9, indicating that the forest is thinly stocked (Table 1). The Scots pine forest extends $3.2 \mathrm{~km}$ in N-S and $2.0 \mathrm{~km}$ in W-E directions. The nearest forest edge that turns into a larger canopy gap is $200 \mathrm{~m}$ west of the measurement site.

Table 1. Height $(H T)$ and stem diameter at breast height $(D B H)$ of seven sample trees (B1 to B7).

\begin{tabular}{ccc}
\hline B & HT (m) & DBH $(\mathbf{c m})$ \\
\hline 1 & 17.6 & 22.6 \\
2 & 18.3 & 25.8 \\
3 & 17.9 & 22.8 \\
4 & 18.0 & 22.6 \\
5 & 16.5 & 27.4 \\
6 & 17.7 & 29.0 \\
7 & 17.5 & 21.8 \\
\hline
\end{tabular}

\subsection{Airflow Measurements}

Airflow was measured at five scaffold towers (To1 to To5) arranged in a cross approximately aligned along the longitudinal axis of the Rhine Valley (Figure 1). The distance between the towers erected at the endpoints of the cross was $48 \mathrm{~m}$. At heights of $21 \mathrm{~m}\left(z_{1}\right.$, $3 \mathrm{~m}$ above the canopy), $18 \mathrm{~m}\left(z_{2}\right.$, at canopy top), $9 \mathrm{~m}\left(z_{3}, 9 \mathrm{~m}\right.$ below the crown space), and $2 \mathrm{~m}\left(z_{4}, 2 \mathrm{~m}\right.$ above the forest floor), 20 ultrasonic anemometers (R.M. Young Company, USA, type 81000VRE) were mounted to To1 to To5 on $1.5 \mathrm{~m}$ long booms to measure the wind vector components in east-west $(u)$, north-south $(v)$, and vertical $(w)$ directions. 
a

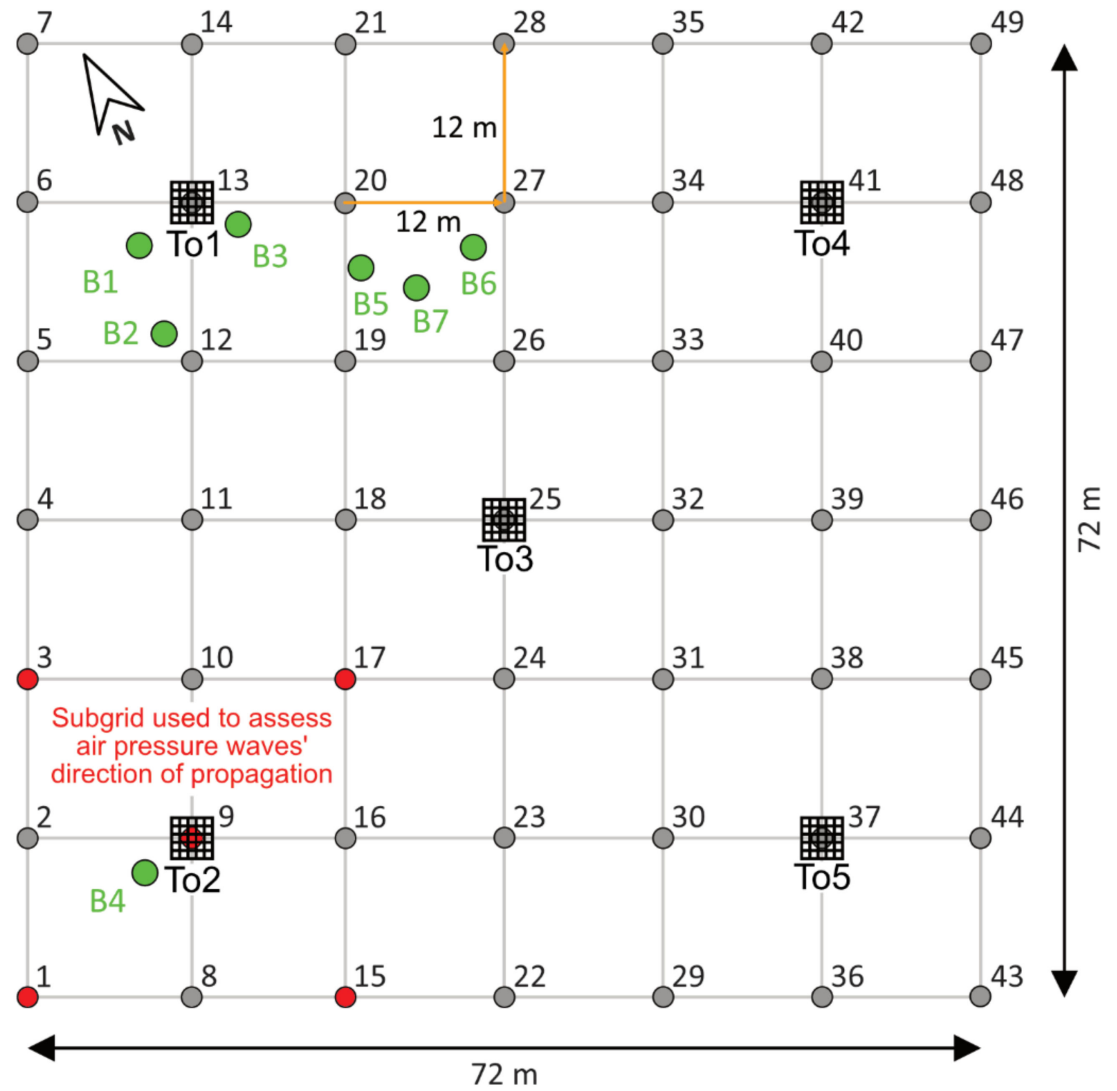

b

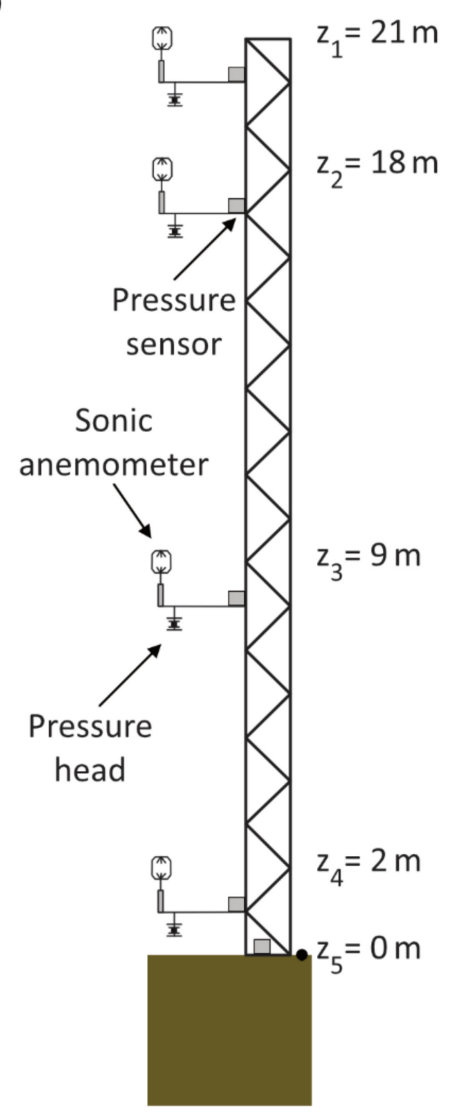

Figure 1. (a) Top view of the air pressure $\left(P_{\text {raw }}\right)$ sensor grid (M1 to M49) at the forest floor $\left(z_{5}=0 \mathrm{~m}\right)$ and the five measurement towers (To1 to To5). The seven sample trees (B1 to B7) are marked with green dots. The five red measurement points (M1, M3, M9, M15, M17) were used to assess the propagation direction of air pressure waves. The orange lines indicate the distance between individual measurement points. (b) Side view of one of the five measuring towers where wind speed $(W S)$, wind direction $(W D)$, and $P_{\text {raw }}$ were measured at multiple heights.

Since northern and southern wind directions dominate at the research site [45], the booms were positioned pointing west to minimize the influence of the towers on the airflow measurements. Wind speed (WS) and wind direction (WD) were calculated from the horizontal wind vector components. For the analysis presented and discussed below, WS was averaged to 10-min mean values, WD was calculated from 10-min mean values of $u$ and $v$. Unless otherwise specified, the WS and $W D$ values always refer to $z_{1}$, i.e., to the above-canopy measurements.

\subsection{Air Pressure Measurements}

Small, wind-induced air pressure fluctuations $\left(P_{\text {raw }}\right)$ were measured using amplified differential piezoresistive pressure sensors (Honeywell, USA, type SSCSNBN001NDAA5) with a range of $\pm 248.84 \mathrm{~Pa}$. The two-port sensors are part of a low-cost, highly precise measuring system developed and evaluated in previous studies [25,46]. One port of the sensors was connected to a pressure reference to attenuate high-frequency $P_{\text {raw }}$ fluctuations. The pressure head used in this study was of the quad-disc type [47,48], made of white $3 \mathrm{~mm}$ PVC sheets and in-house 3D-printed parts.

At the forest floor $\left(z_{5}=0 \mathrm{~m}\right), 49$ air pressure sensors were installed in a $7 \times 7$ regular grid with a $12 \mathrm{~m}$ distance between the measurement points (M1 to M49). The dimensioning of the measuring grid was based on the findings on the correlation of air pressure fluctuations obtained in an earlier investigation at the research site [35]. They reported a 
strong correlation of air pressure fluctuations up to a horizontal distance of $15 \mathrm{~m}$ above the forest floor. In addition, To1 to To5 carried sensors to measure air pressure fluctuations at $z_{1}-z_{4}$. The air pressure measuring systems were mounted on the same booms carrying the sonic anemometers.

The radiometric analog outputs of all air pressure sensors were read using an Arduino Nano based microcontroller. An ethernet shield (type Wiznet W5100 Ethernet-Chip) was connected to the Arduino Nano to send $P_{\text {raw }}$ data to a central microcomputer (type Raspberry Pi 3 Model B+, Raspberry Pi Foundation, UK) using the message queuing telemetry transport (MQTT) communication protocol.

The $P_{\text {raw }}$ time series were first band-pass filtered for the frequency range $0.01-0.10 \mathrm{~Hz}$ $(P)$ which controls pressure pumping $[25,35]$. To assess the aggregated strength of the $P_{\text {raw }}$ fluctuations, PPC was calculated over 10-min intervals:

$$
P P C=s f \times \frac{1}{N} \times \sum_{n=1}^{N}|\Delta P|
$$

with $s f$ being the sampling frequency, $N$ is the number of $P_{\text {raw }}$ measurements in a $10-\min$ interval, and $\Delta P$ is the difference between two successive $P$ values.

Since wind-tree interactions are commonly analyzed using wind speed at or above canopy top $[22,23,49,50]$, the functional dependence in 10-min intervals of above-canopy WS measured at $z_{1}$ and PPC estimated at $z_{5}$ was established with a power law. The fit of the power law to the data was always better than the fit of other simple linear regression models:

$$
P P C=a_{1} \times W S^{a_{2}}+a_{3}
$$

where $a_{1}, a_{2}$, and $a_{3}$ are coefficients. The power law was fitted using WS measured at To1 to To5 and the PPC values computed at M1 to M49 (PPC 1 to $\left.P P C_{49}\right)$, yielding 20 tower-related and 49 measurement grid-related empirical models.

The direction of $P$ propagation $(P D)$ was calculated using the approach reported in a previous study [35]. Instead of using maxima of cross-correlation functions calculated between $P$ time series, the simultaneous occurrence of $P$ maxima was utilized to determine propagation characteristics of air pressure waves moving across M1, M3, M9, M15, and M17 aligned in the shape of a cross in the southwestern corner of the ground-level air pressure measurement grid. The location of the sensor cross was chosen because the southwestern corner of the measurement grid is the first to be impacted. Due to the similarity of the air pressure measurements, which will be illustrated later, the evaluated sensor cross could also have been positioned at any other location of the measurement grid. The air pressure waves' motion was analyzed only when all five $P$ time series at M1, M3, M9, M15, and M17 showed at least one peak in the investigated 10-min intervals. The peak selection was based on Matlab's (The MathWorks Inc., Natick, Massachusetts) findpeaks function [51] using a data-specific combination of peak prominence of 0.6 and a peak width of 120 values as selection criteria.

Starting from the central measurement point M9, the time differences to the four measurement points at the corners of the measurement cross were quantified. Based on the time differences, the direction of propagation of all examined air pressure waves was then determined and averaged.

\subsection{Tree Motion Measurements}

Wind-induced stem tilt of seven Scots pines (B1 to B7) was measured in $x\left(t_{\mathrm{x}}\right)$ and $y\left(t_{\mathrm{y}}\right)$ directions over the height range 2.4 to $2.8 \mathrm{~m}$ using the Tree Response Sensor (TRS) which is part of the Tree Motion Monitoring System (TreeMMoSys) developed in an earlier study [52]. The height range corresponds to $1 / 7$ of the tree height $(H T)$, where the first antinodal point of vibration of a clamped-free beam was assumed [53]. Tree response data were collected wirelessly and stored on a ground receiver using TreeMMoSys. 
To investigate the integral response of the aerial tree parts to the wind, as in a previous study [21], the stem tilt vector $(T)$ was calculated from $t_{\mathrm{x}}$ and $t_{\mathrm{y}}$ for B1 to B7:

$$
T=\sqrt{t_{x}^{2}+t_{y}^{2}}
$$

The $T$ values were used to calculate 10 -min mean interval values $\left(T_{\text {mean }}\right)$ and 98 th percentiles $\left(T_{98}\right)$. While $T_{\text {mean }}$ was used to assess the mean response of B1 to B7 to the wind, $T_{98}$ was used to quantify the impact of strong and short-term wind loading from turbulent airflow components.

\subsection{Bi-Orthogonal Decomposition}

To reduce the dimensions of the spatiotemporal dynamics of $W S$ and $P$, the biorthogonal decomposition (BOD) was applied [54]. BOD can capture important common time-space characteristics in high-dimensional data. The five 10-min above-canopy WS time series and the 49 below-canopy $P$ time series were compiled into space-time signals (C) each and decomposed [46]:

$$
C(q, t)=\sum_{m=1}^{\infty} \alpha_{m} \times \mu_{m}(t) \times v_{m}(q)
$$

where $m$ is the number of BOD components, $\alpha_{m}=\sqrt{\lambda_{m}}$ are weighting factors, $\lambda_{m}$ are eigenvalues, $\mu_{m}(t)$ are temporal modes, $v_{m}(q)$ are spatial modes, and $\left(\mu_{m}(t), v_{m}(q)\right)$ form a set of normalized orthogonal functions. The Kaiser criterion [55], defined as the mean of all eigenvalues, was used to determine the number of informative BOD components in the decomposed $W S\left(W S_{\mathrm{BOD}}\right)$ and PPC (PPC $\left.\mathrm{BOD}\right)$ time series useful for further analysis.

As a surrogate for the actual mean wind load on the sampled trees, which is still unknown, squared $W S_{\mathrm{BOD}}\left(W S_{\mathrm{BOD}}^{2}\right)$ and $P P C_{\mathrm{BOD}}$ were used. Both variables potentially provide information about the temporal dynamics of tree motion but are not an expression of the effective wind load defined in a previous study [19]. The 98th percentiles of $P\left(P_{98}\right)$ were used as surrogate values to simulate gust speed in the 10-min intervals. Gust speed was previously used to represent the impact of strong and short-term wind loads on trees in forests [56-59].

\subsection{Wavelet Analysis}

As demonstrated below, $P P C_{\mathrm{BOD}}$ is used to approximate wind speed at various heights above ground, including below-canopy wind speed. However, this article focuses on the above-canopy wind speed. For a general illustration of the approach's potential, wavelet coherence $(W C o h)$ is used as a local correlation measure. It was calculated to measure the 10-min localized correlation between $W S_{\mathrm{BOD}}$ and $P P C_{\mathrm{BOD}}$ in the study period over 106 scales [60]:

$$
W C o h=\frac{\left|S\left(F_{\mathrm{WS}}^{*}(b, c) \times F_{\mathrm{PPC}}(b, c)\right)\right|^{2}}{S\left(\left|F_{\mathrm{WS}}(b, c)\right|^{2}\right) \times S\left(\left|F_{\mathrm{PPC}}(b, c)\right|^{2}\right)}
$$

where $F_{\mathrm{WS}}(b, c)$ and $F_{\mathrm{PPC}}(b, c)$ are continuous wavelet transforms of $W S_{\mathrm{BOD}}$ at $z_{1}$ to $z_{4}$ and $P P C_{\mathrm{BOD}}$ with the analytic Morlet wavelet at scales $b$ and positions $c$ along the timeline. The asterisk denotes the complex conjugate, and $S$ indicates smoothing in space and time over 12 scales.

\subsection{Modeling of Tree Reactions to Short-Term Wind Loading}

The ensemble learning method bootstrap aggregating (bagging) was used to model $T_{98}\left(T_{98, \text { mod }}\right)$. The bagging algorithm averages predictions from multiple regression models to reduce the variance in the prediction by minimizing the mean squared error [61]. The bootstrap procedure was applied to $H=10$ randomly sampled unweighted subsets of the 
predictors $T_{\text {mean }}$ and $P_{98}$ per Scots pine tree to train ten tree-specific regression models $\left(G_{h}\right.$ with $h=1, \ldots, 10)$ :

$$
G_{\text {mean }}=\frac{1}{H} \sum_{h=1}^{H} G_{h}
$$

Examination of the predictive accuracy based on the coefficient of determination $\left(R^{2}\right)$ of different predictor combinations revealed that $T_{\text {mean }}$ and $P_{98}$ are best suited for predicting $T_{98}$. It is plausible to assume that high $T_{98}$ is coupled with high $T_{\text {mean }}$. Since the relationship between $T_{\text {mean }}$ and $T_{98}$ is not strictly linear, $P_{98}$ was used as a surrogate for considering the short-term impact of gust speed on stem tilt. To measure the prediction accuracy and prevent overfitting, out-of-bag subsets that were not used to train the regression models were evaluated.

All calculations were made using Mathworks' Matlab ${ }^{\circledR}$ Software (Release 2020b; The MathWorks Inc., Natick, MA, USA).

\section{Results and Discussion}

\subsection{Wind Speed above and below the Canopy}

During the study period, WS averaged across To1 to To5 varied between 0.2 and $5.7 \mathrm{~m} / \mathrm{s}$. Above-canopy $W S_{\text {mean }}=1.63 \mathrm{~m} / \mathrm{s} \pm 0.11$ (mean \pm standard deviation) indicate very similar wind speed conditions measured over the whole study period at the research site (Figure 2a).

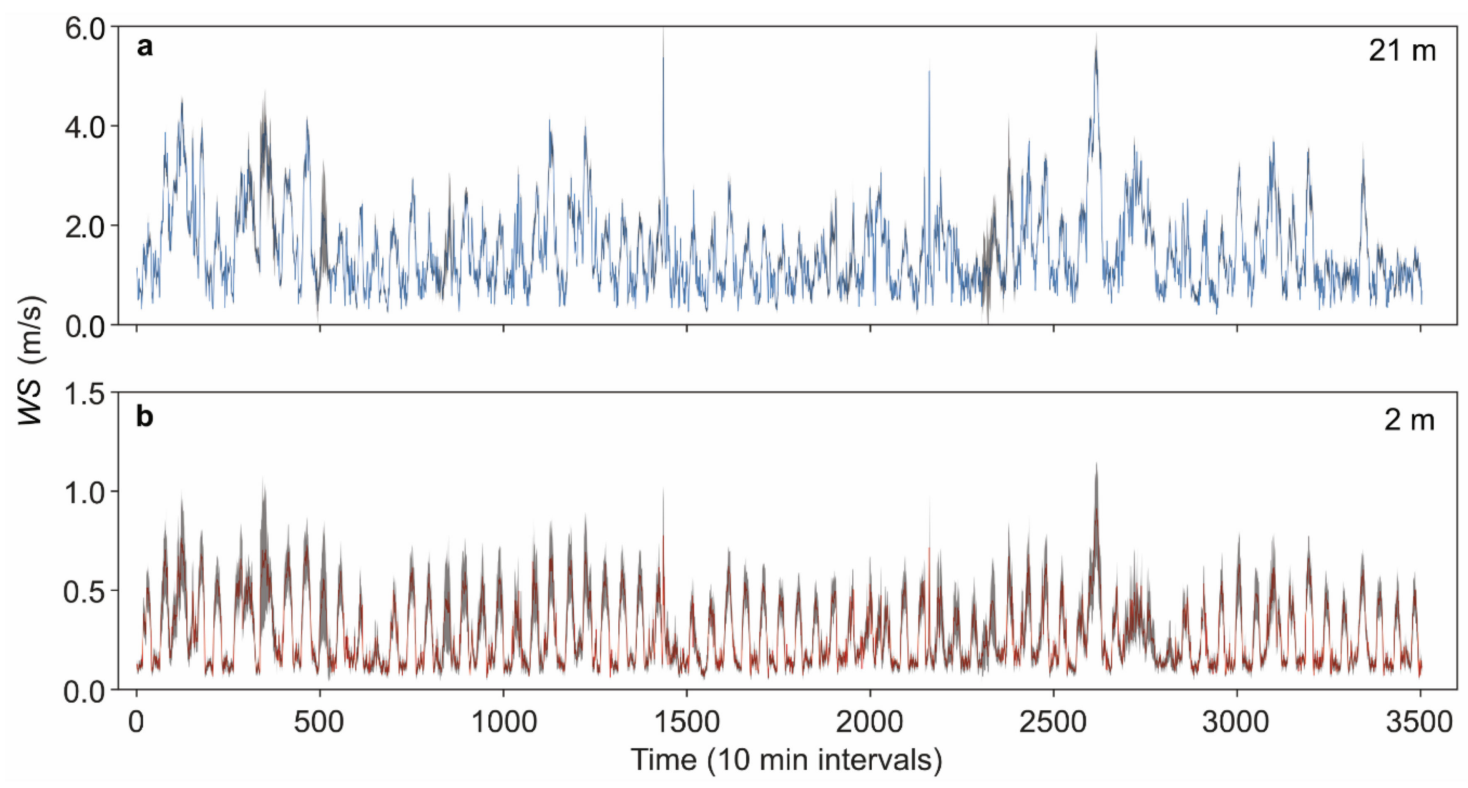

Figure 2. 10-min wind speed (WS) averaged across the measurement towers 1 to 5 (To1 to To5) from 3 to 28 July 2020 at the heights (a) $z_{1}=21 \mathrm{~m}$ (blue line, above the canopy) and (b) $z_{4}=2 \mathrm{~m}$ (red line, above the forest floor). The gray areas indicate one standard deviation of WS at the respective measuring heights.

At the forest floor, averaged WS values were much lower, mostly ranging between 0.1 and $0.7 \mathrm{~m} / \mathrm{s}$ with $W S_{\text {mean }}=0.23 \pm 0.07 \mathrm{~m} / \mathrm{s}$ (Figure $2 \mathrm{~b}$ ). Although the standard deviation of $W S$ at the ground obviously exhibits larger relative variability, it was in a similar range in absolute terms as the wind speed variation at $z_{1}$.

At both heights, WS is subject to pronounced daily variations on many days. The variations occur more regularly at $z_{4}$ than at $z_{1}$. The highest $W S$ values mainly happen during the day. The daily component in the WS time series can be attributed to the location of the research site in the Upper Rhine valley, where tertiary circulation systems develop recurrently [44]. A secondary, below-canopy wind speed maximum that could result from thermal stability conditions [62] and mean horizontal air pressure gradients [63,64] was 
observed in 3.8\% of all 10-min intervals. A systematic wind direction shear resulting from air pressure conditions in the below-canopy space as reported in a previous study [63] was not found. It is likely that the below-canopy wind direction distributions determined at To1 to To5 reflect the local wind field influenced by the surrounding trees and understorey.

\subsection{Air Pressure Fluctuations below the Canopy}

Below-canopy $P$ ( $z_{3}$ to $z_{5}$ ) values under different above-canopy wind conditions are shown over two different 10-min intervals in Figure 3. With an above-canopy WS $=0.6 \mathrm{~m} / \mathrm{s}$ measured at To1, corresponding to the 10th percentile of the To1 wind speed distribution, below-canopy $P$ is small, mostly varying between -0.30 and $0.30 \mathrm{~Pa}$.
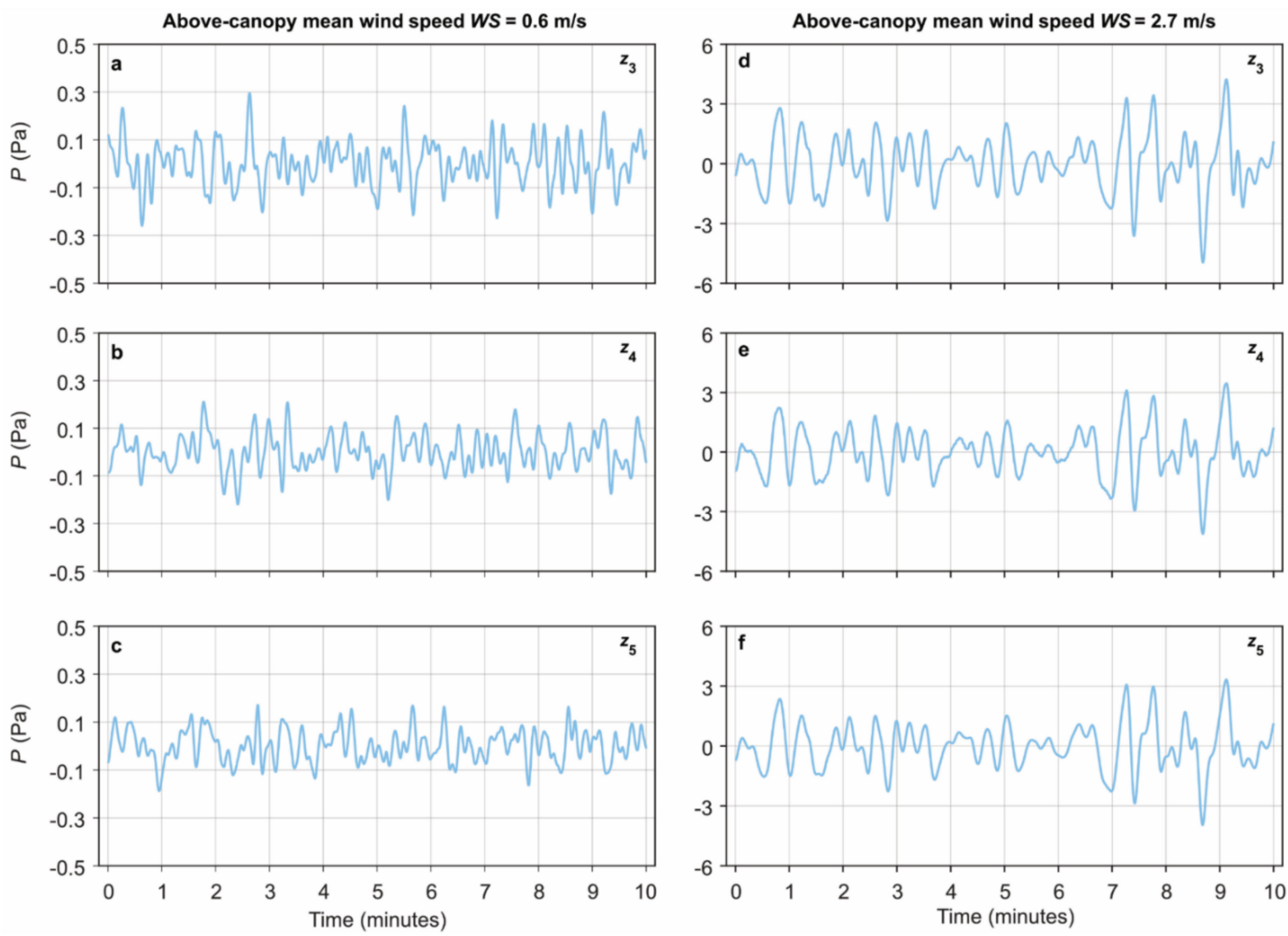

Figure 3. Examples of 10-min band-pass filtered air pressure fluctuations $(P)$ measured at tower 1 (To1) at different heights $\left(z_{3}=9 \mathrm{~m}\right.$ to $z_{5}=0 \mathrm{~m}$ under varying above-canopy wind speed (WS) conditions, $(\mathbf{a}-\mathbf{c}) W S=0.6 \mathrm{~m} / \mathrm{s}$ and $(\mathbf{d}-\mathbf{f}) W S=2.7 \mathrm{~m} / \mathrm{s}$.

With an above-canopy WS $=2.7 \mathrm{~m} / \mathrm{s}$, representing the 90th percentile of the To1 wind speed distribution, below-canopy $P$ measurably increases and fluctuates between -6.0 and 4.0 Pa. In addition to the magnitude of the $P$ fluctuations, their similarity across heights $z_{3}$ to $z_{5}$ also increased with increasing above-canopy wind speed.

If all 10-min intervals of the study period are included, the mean values of the Pearson correlation coefficient $(R)$ calculated between below-canopy $P$ time series increased with increasing above-canopy WS from $R=0.76$ at $W S<1.0 \mathrm{~m} / \mathrm{s}$ to $R=0.96$ at $W S>4.0 \mathrm{~m} / \mathrm{s}$. The same tendency was found in the correlation of the 10-min mean $P$ values in dependence of WS. With increasing above-canopy WS measured at To1, the correlation strength rose from $R=0.78$ to $R=0.98$.

Previous studies also reported a correlation that increases with higher WS between below-canopy $P$ and above-canopy WS $[25,26]$. In a further study, it was demonstrated that the propagation of $P$ could also be represented as a function of above-canopy WD [35]. 
However, although an earlier study narrowed the frequency range of wind-induced pressure fluctuations over forest [25], their origin is still unclear. This is not at least because only a few studies reported results from direct measurements of wind-induced air pressure fluctuations $[25,26,35,37,38,65]$.

Air pressure fluctuations at the forest floor can result from turbulence induced by local airflow-forest-interactions when shear instability at the canopy top generates coherent structures [30]. In turbulent canopy airflow, these coherent structures are responsible for efficient transport of heat and momentum between forests and the atmosphere [31-33]. However, the results of previous studies are ambiguous. One study was able to demonstrate that air pressure fluctuations measured below a deciduous forest canopy are strongly correlated with the passage of coherent turbulent structures $[27,28]$. Another study investigating coherent structures in a Scots pine forest did not find such a correlation [45].

The temporal and spatial similarity of $10-\mathrm{min} P P C_{1}$ to $P P C_{49}$ was strong. The 10-min $P P C$ values were averaged to hourly values for clarity in Figure 4 . Based on these hourly values, the daily $P P C_{1}$ to $P P C_{49}$ cycles in the measurement grid can be better visualized.
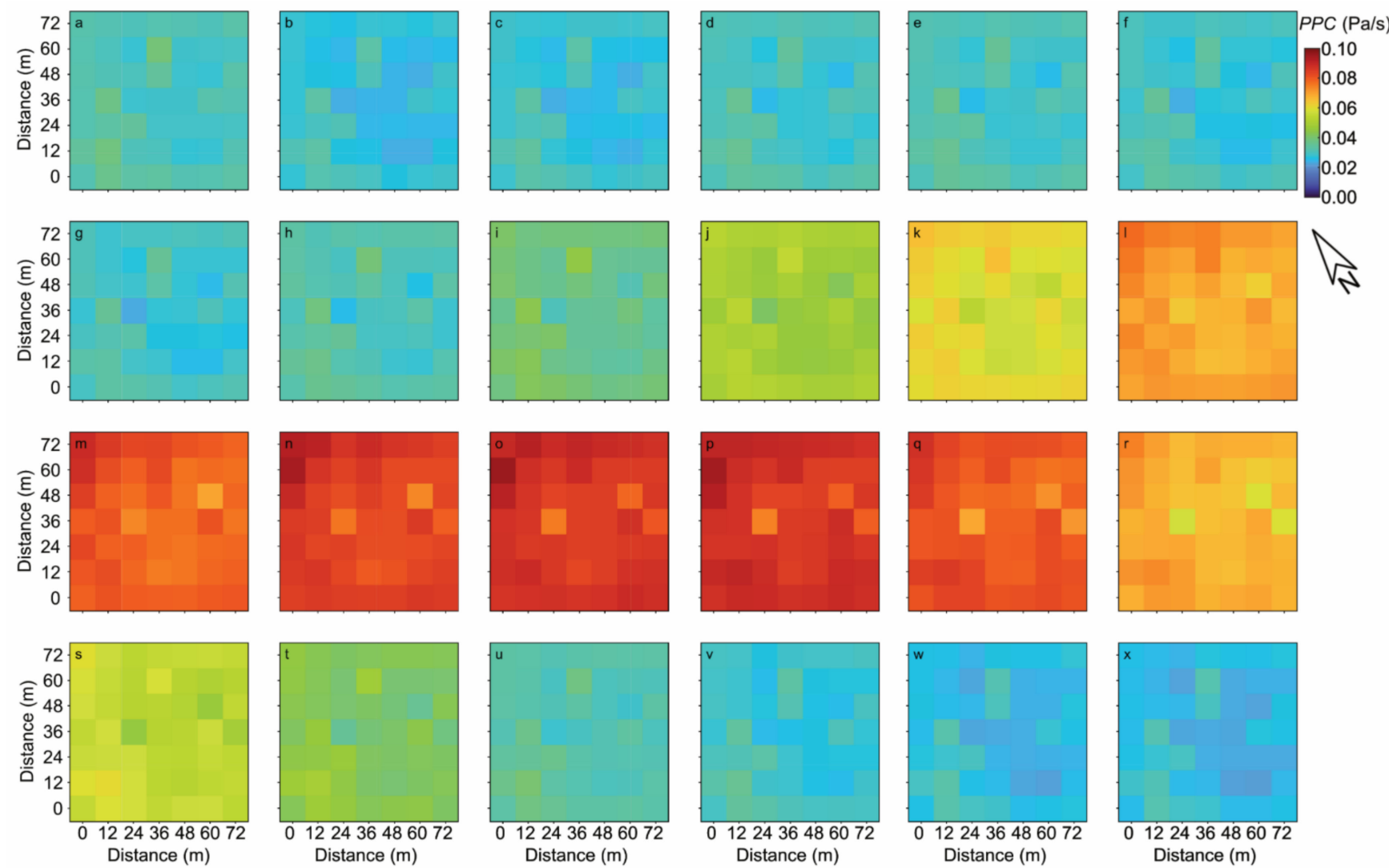

Figure 4. (a-x) Spatial variation in mean hourly (0:00-23:00 CET) pressure pumping coefficient (PPC) values representing the mean daily PPC cycles for the period 3 to 28 July 2020 at measurement points 1 to 49 (M1 to M49).

All points in the measurement grid showed a pronounced mean daily PPC cycle with the highest hourly values of $0.08 \mathrm{~Pa} / \mathrm{s}$ and more from 13:00 to 15:00 CET. During these hours, above- and below-canopy WS recurrently reached the highest mean values during the day. The lowest $P P C$ values of $0.04 \mathrm{~Pa} / \mathrm{s}$ and less regularly occurred from 22:00 to 7:00 CET. The intra-hourly spatial PPC differences in the measurement grid are negligible, varying mainly in the narrow range $-0.007 \mathrm{~Pa} / \mathrm{s}$ to $0.008 \mathrm{~Pa} / \mathrm{s}$ throughout the day.

The low spatiotemporal variability of the above-canopy WS and below-canopy PPC can be represented by only one BOD component, as evaluated by the Kaiser criterion (Figure 5). Due to the similarity of the above-canopy WS measured at To1 to To5, the first 
BOD component $\left(W S_{\mathrm{BOD}}\right)$ explains $98 \%$ of the variance $(E V)$ in the above-canopy WS time series. The high similarity between $P P C_{1}$ to $P P C_{49}$ values is also demonstrated by the value of $E V=98 \%$ associated with the first BOD component $\left(P P C_{\mathrm{BOD}}\right)$. For the analyzed $W S$ and PPC data, three separate BOD components each are sufficient to explain almost all of each variable's spatiotemporal variability at the research site.
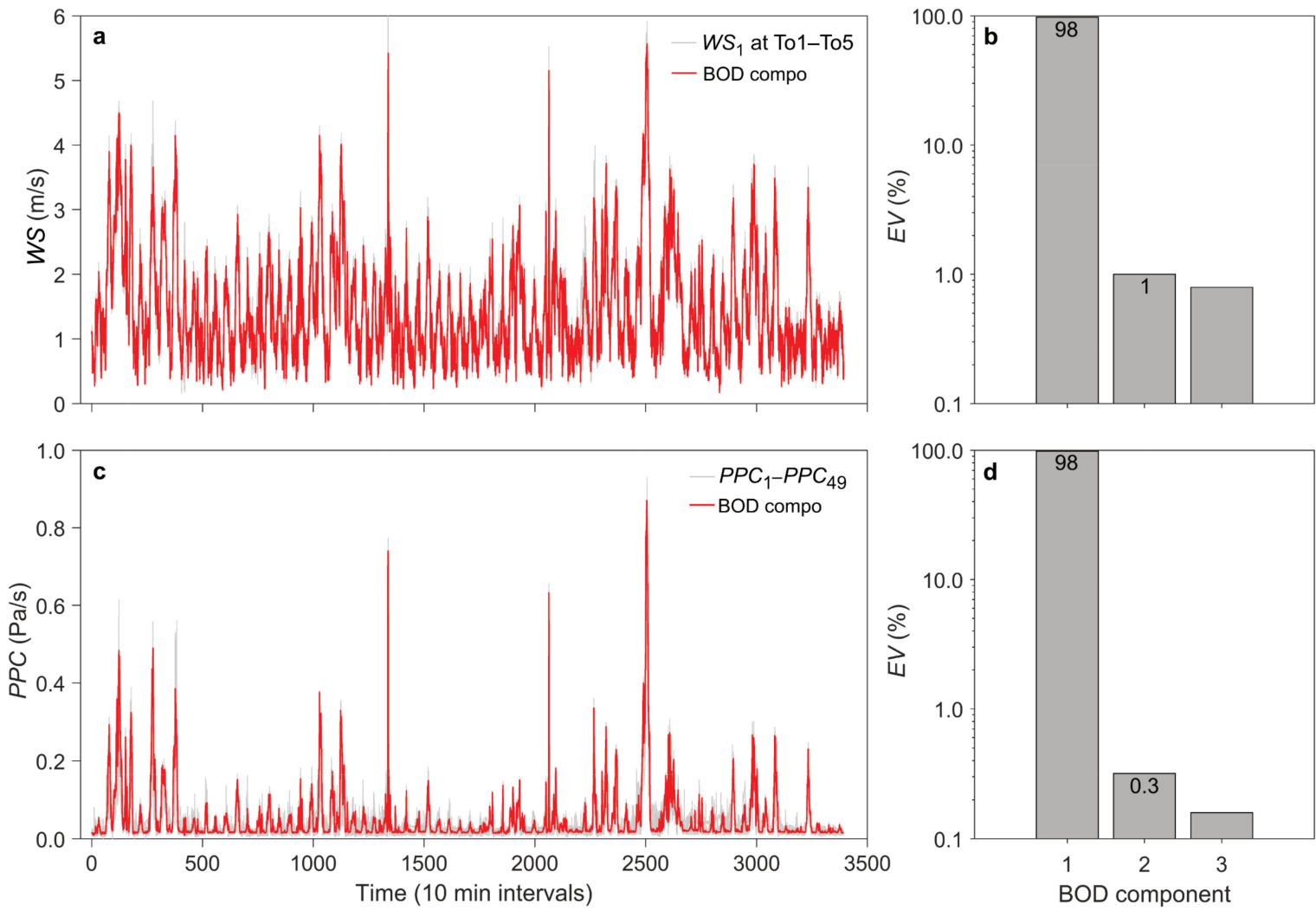

Figure 5. (a) Above-canopy wind speed (WS) measured at towers 1 to 5 (To1 to To5) from 3 to 28 July 2020 together with the first component of the bi-orthogonal decomposition (BOD) used to assess the dominant features of the WS variability. (b) Explained variance $(E V)$ using the first three BOD components in the WS time series. (c) Pressure pumping coefficients $(P P C)$ values calculated at measurement points 1 to $49\left(P P C_{1}\right.$ to $\left.P P C_{49}\right)$ together with the first BOD component used to assess the dominant features of the below-canopy $P P C$ variability. (d) $E V$ of the first three BOD components in the $P P C_{1}$ to $P P C_{49}$ time series.

The mean daily cycles of WCoh show the highest values from 12:00 to 20:00 CET (Figure 6). This reflects the daily variation of $W S_{\mathrm{BOD}}$ at the research site, which, as indicated earlier, has a maximum in the afternoon. With higher $W S_{\mathrm{BOD}}$, the amplitudes of $P$ and the $P P C$ values increase, as has been demonstrated in previous studies $[25,26]$. Over the day, the $W C o h$ levels at $z_{1}$ and $z_{2}$ are similar, with strong above-canopy $W C o h=0.79$ representing the highest 10-min overall value at 15:10 CET. There is a height-dependent lag between the maximum WCoh values, which cannot yet be explained. The highest WCoh values are reached latest in the day at $z_{4}$. At night, when $W S_{\mathrm{BOD}}$ is low, WCoh is also low. The lowest $W S_{\mathrm{BOD}}$ values are found at all measurement heights between 2:00 and 6:00 CET in the morning. 


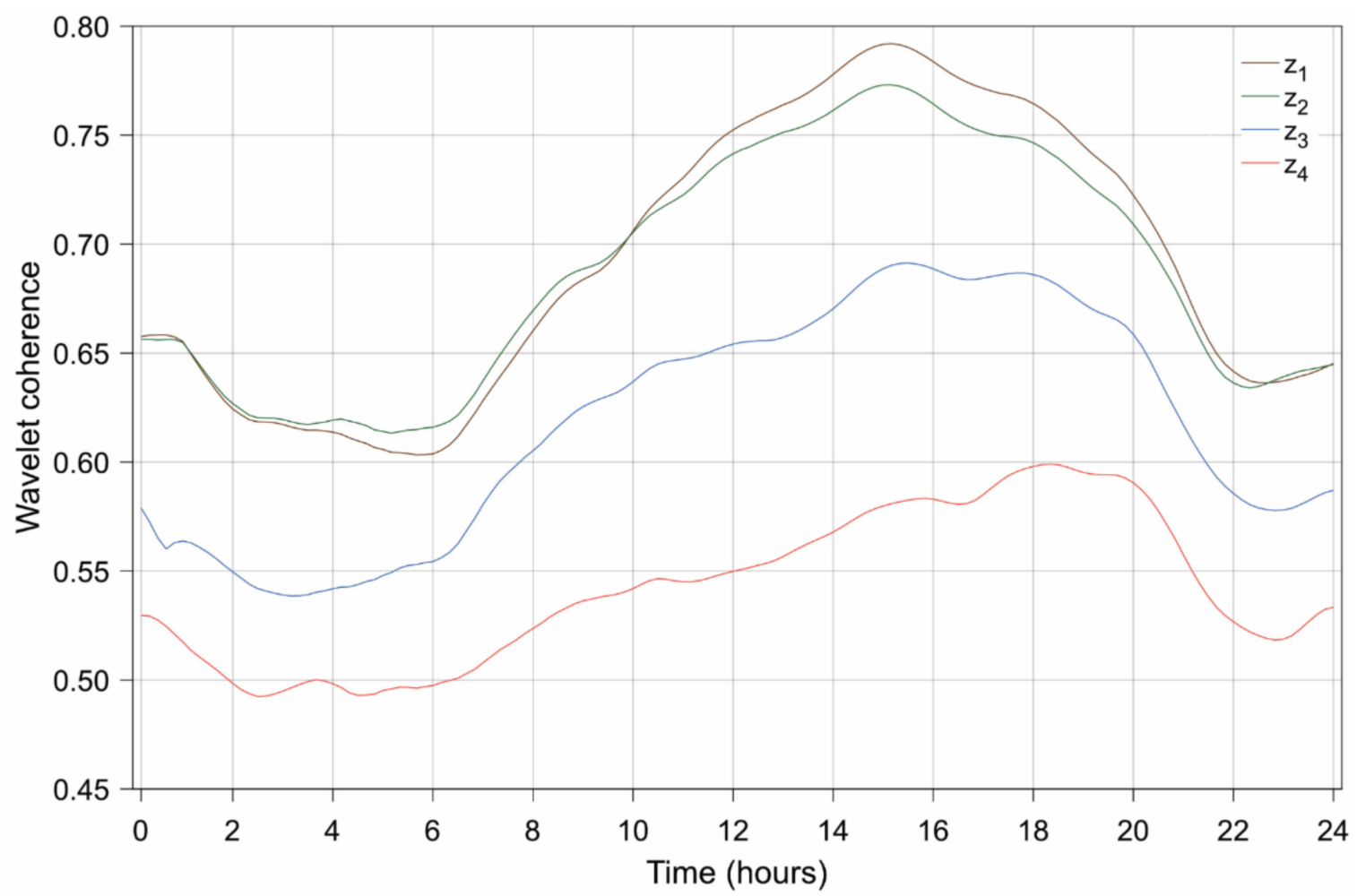

Figure 6. Mean daily cycles of wavelet coherence (WCoh) calculated from the first components of the bi-orthogonal decomposition (BOD) of wind speed $\left(W S_{\mathrm{BOD}}\right)$ available at the measurement heights $z_{1}=21 \mathrm{~m}$ to $z_{4}=2 \mathrm{~m}$ and the pressure pumping coefficient $\left(P P C_{\mathrm{BOD}}\right)$ available at the forest floor.

When WCoh is averaged over the entire study period, its decrease with reduced height above the ground becomes apparent. From $z_{1}$ to $z_{4}$, the study period mean values of WCoh are $0.69,0.69,0.62$, and 0.55 . Although the level of correlation decreases from above the forest toward the forest floor, the association between $W S_{\mathrm{BOD}}$ and $P P C_{\mathrm{BOD}}$ is sufficient to model wind speed from $z_{3}$ to $z_{1}$ with reasonable certainty using $P P C$. The consistent lower level of wavelet coherence toward the forest floor undermines the findings of previous studies $[27,28,34]$ of a dominant modulation of the near-surface air pressure pattern by coherent structures.

\subsection{Approximation of Wind-Induced Tree Motion}

The dependence of $P P C_{\mathrm{BOD}}$ on $W S_{\mathrm{BOD}}^{2}$ is strong. As known from previous studies at the research site $[25,26,35]$, below-canopy $P P C$ is high when above-canopy WS is high and vice versa. This relationship is very well reproduced $\left(R^{2}=0.95\right)$ by the power law (Figure 7a). The high $E V$ values associated with the first BOD components, together with the strong correlation between $W S_{\mathrm{BOD}}$ and $P P C_{\mathrm{BOD}}$, show that a single below-canopy $P$ measurement would have been sufficient to calculate above-canopy WS. In future investigations, such an elaborate measurement system as presented in this paper will no longer be necessary. 

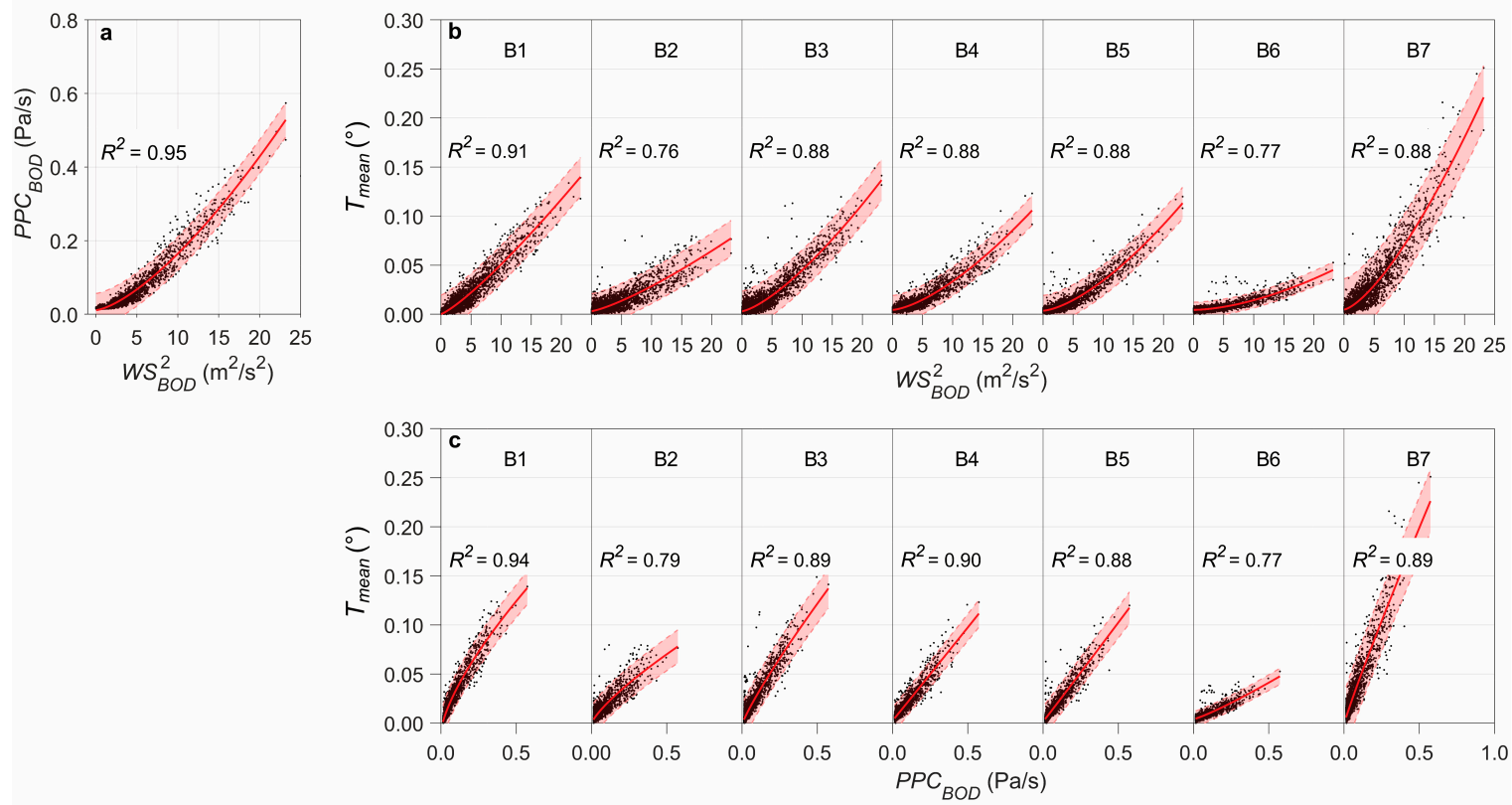

Figure 7. (a) Functional (power law) dependence of the first $P P C$ bi-orthogonal component $\left(P P C_{\mathrm{BOD}}\right)$ on the square of the first WS bi-orthogonal component $\left(W S_{\mathrm{BOD}}^{2}\right)$. Functional (power law) dependence of the 10-min mean stem tilt vector $\left(T_{\text {mean }}\right)$ of seven sample trees (B1 to B7) on (b) $W S_{\mathrm{BOD}^{\prime}}^{2}$ and (c) $P P C_{\mathrm{BOD}}$. The red areas indicate the prediction confidence intervals for new observations of $T_{\text {mean }}$ at the $95 \%$ level.

Since the functional dependence of $P P C_{\mathrm{BOD}}$ on $W S_{\mathrm{BOD}}^{2}$ is strong, $P P C_{\mathrm{BOD}}$ was used as a predictor for $T_{\text {mean }}$ of trees $\mathrm{B} 1$ to $\mathrm{B} 7$ and compared to the dependence of $T_{\text {mean }}$ on $W S_{\mathrm{BOD}}^{2}$. Figure $7 \mathrm{~b}$ shows the response of the sample trees' stems to $W S_{\mathrm{BOD}}^{2}$ together with the power law curves. Although B1 to $\mathrm{B} 7$ responded slightly different to $W S_{\mathrm{BOD}}^{2}$, the functional dependence of $T_{\text {mean }}$ on $W S_{\mathrm{BOD}}^{2}$ is always strong, which is expressed by the high $R^{2}$ values, all exceeding $R^{2}=0.75$. Stem tilt was lowest for the thickest tree (B6), and largest for the tree with the thinnest stem (B7).

The dependence of $T_{\text {mean }}$ on $P P C_{\mathrm{BOD}}$ exhibits different tree-specific power law curves compared to the curves calculated between $T_{\text {mean }}$ and $W S_{\mathrm{BOD}}^{2}$ (Figure 7c). However, the strength of the relationship is no less than between $T_{\text {mean }}$ and $W S_{\mathrm{BOD}}^{2}$, as indicated by $R^{2}>0.75(p=0.00)$. Thus, with the comparable strength of the functional relationships, it is possible to use ground-based $P$ to approximate the wind conditions above the Scots pine forest that drive stem tilt of B1 to B7 and to therefore model $T_{\text {mean }}$.

In addition to $T_{\text {mean }}$ determined by mean wind loads, large stem tilt far from the central tilt tendencies at the upper tail of the $T$ distribution represented by $T_{98}$ are also of great interest for the analysis of wind-induced tree response. They are indicators of the trees' maximum resistance to wind loads caused by the turbulent airflow. Therefore, Figure 8 illustrates the potential of using the combination of $T_{\text {mean }}$ and $P_{98}$ as predictors for modeling $T_{98}$.

The displayed point clouds cluster around the 1:1-lines. The scatter of the points is very low. Measured by the coefficient of determination, the results of the regression-based modeling are convincing for all sample trees $\left(R^{2} \geq 0.88\right)$. The simple regression models can reproduce tree-individual differences in $T_{98}$ as a function of $T_{\text {mean }}$ and $P_{98}$. While the small diameter tree B7 responded most strongly to the extreme wind loads, the large diameter tree $\mathrm{B} 6$ shows the smallest $T_{98}$ values. This is a response pattern that was already described when discussing $T_{\text {mean }}$. 

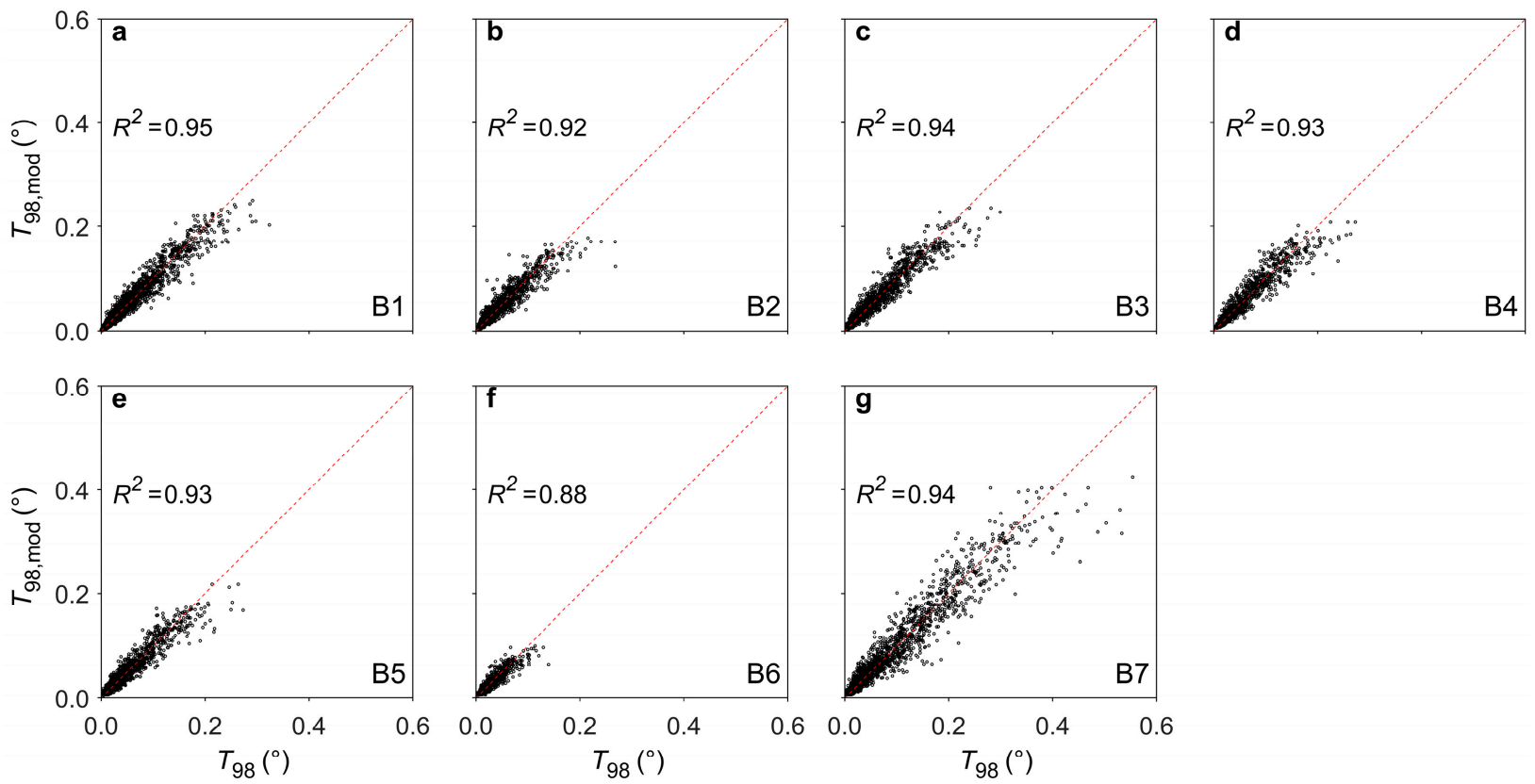

Figure 8. Modeled 98th percentiles of stem tilt $\left(T_{98, \text { mod }}\right)$ of the sample trees $(\mathbf{a}-\mathbf{g})$ B1-B7 against the 98th percentiles of measured stem tilt $\left(T_{98}\right)$. The 1:1 lines are dashed red.

For modeling of $T_{98}$, the relative importance of $T_{\text {mean }}$ was $71 \pm 6 \%$. The relative importance of $P_{98}$ equaled $29 \pm 6 \%$. The magnitude of the predictor importance ratio results from the low mean wind and gust speed levels during the study period. At low wind loading, $T_{98}$ is closely coupled to $T_{\text {mean }}$. Under these wind conditions, the impact of sporadic, intense short-term wind loads due to high gust speed as approximated by $P_{98}$ is not expected.

The distribution of the local wind direction observed above the canopy at To1 and To2 is shown in Figure 9a in the form of wind roses. The wind roses displaying the wind direction distributions were created using the 10-min mean horizontal wind vector components. The wind direction distributions are bimodal but different. Southern and north-northwestern directions along the longitudinal axis of the Upper Rhine valley dominate the distributions. Few values were observed for easterly southeasterly directions, i.e., more across the lateral axis of the Upper Rhine valley.

A similar distribution, but more sharply divided into two sectors, is found from the $P$ propagation direction values (Figure $9 \mathrm{~b}$ ). The wind roses displaying the $P$ propagation direction distributions were created using the 10-min mean values of the time differences of $P$ maxima during the passage of $P$ waves across M1, M3, M15, M17, and M9. The values are more concentrated in the two ranges 135 to $180^{\circ}$ and 315 to $360^{\circ}$. Almost no values were determined from westerly and easterly directions.

In Figure 9c,e,g, the $T_{98}$ shares of B1, B2, and B7 are shown per wind direction sector by radial bar plots. The radial bar plots were chosen instead of the wind rose plots because the directional distribution of $T_{98}$ and not $T_{\text {mean }}$ is shown as a function of the WD distribution. The radial bar plots illustrate the $T_{98}$ distribution as a function of $W D$.

Depending on $W D$ at To1 and To2, $T_{98}$ shares occur across all sectors, with tree-specific differences in magnitude. There is hardly any dependence on wind direction. In addition, the $T_{98}$ shares differ per sector. While B2 shows the weakest response to wind loading, the wind-induced response of B7 is most vigorous. 

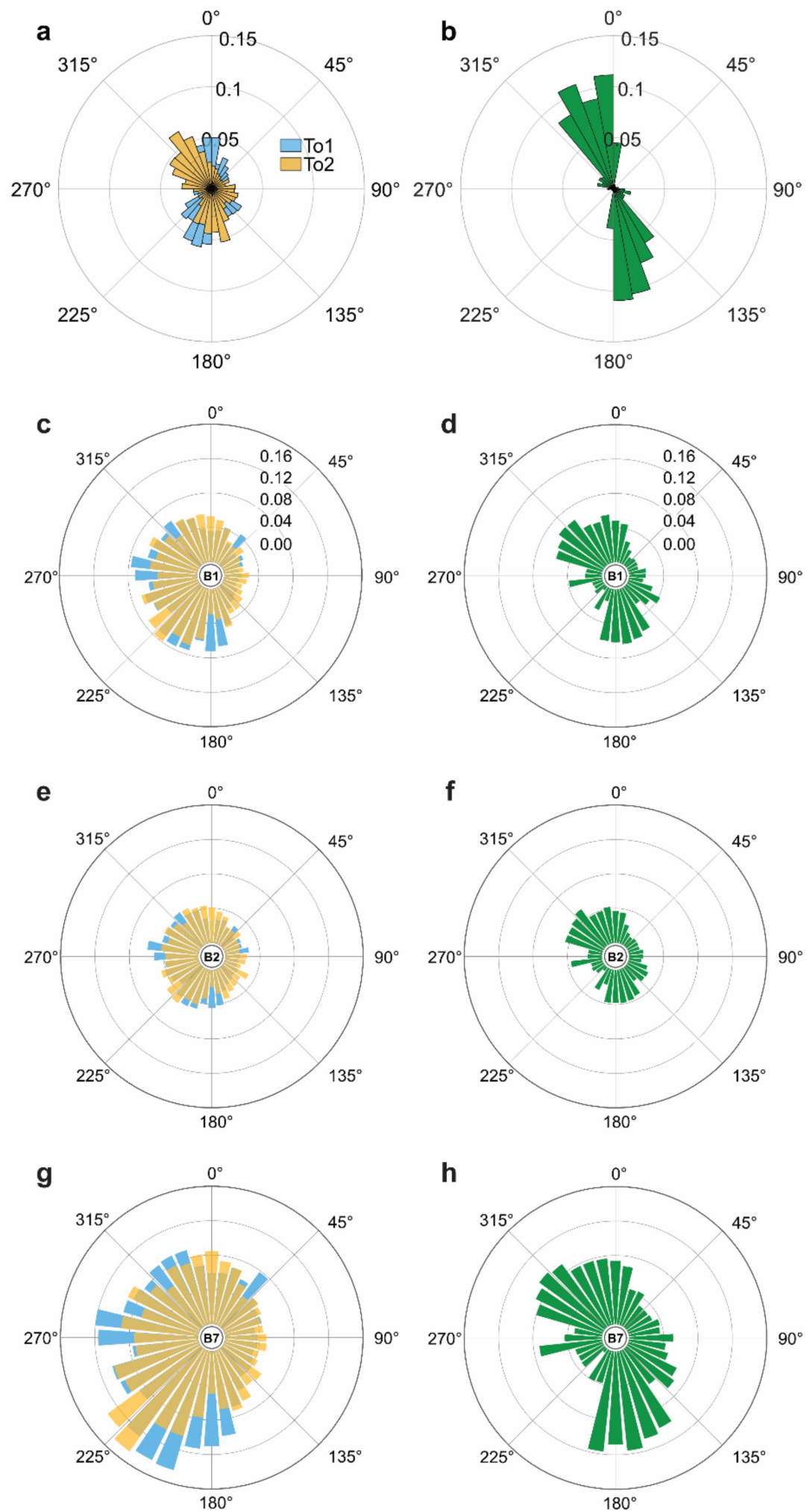

Figure 9. Wind rose plots of (a) wind direction (WD) observed at towers 1 (To1, blue bars) and 2 (To2, yellow bars) at the height $z_{1},(\mathbf{b})$ mean propagation direction of air pressure fluctuation waves $(P D)$ determined at the forest floor $\left(z_{5}=0 \mathrm{~m}\right)$ in the subgrid consisting of the measurement points M1, M3, M9, M15, and M17. (c,e,g) Radial bar plots of WD-dependent 98 percentile stem tilt $\left(T_{98}\right)$ of sample trees 1 (B1), 2 (B2), and 7 (B7), (d,f,h) PD-dependent $T_{98}$ of B1, B2, and B7. 
The wind-induced motion patterns of B1, B2, and B7 as a function of mean $P$ propagation direction are shown in Figure $9 \mathrm{~d}, \mathrm{f}, \mathrm{h}$. The radial bar plots show the $T_{98}$ distribution as a function of $P D$. The sectoral distribution of the highest $T_{98}$ values differs from the distributions shown as a function of $W D$. The values are more closely distributed within the two directional sectors where the mean $P$ propagation directions occurred most frequently.

At this point, it can only be speculated about the reasons for the differences in the representations of the direction-dependent tree motion. A plausible assumption is that the wind speed measurement is more influenced by the local measurement environment than the air pressure measurement. Taking this reasoning further, it is necessary to plan the position of the airflow measurement even more precisely in future studies of wind-tree interactions than has been the case in the past.

The results obtained for $P P C_{\mathrm{BOD}}, P_{98}$, and $P D$ are closely related to $W S_{\mathrm{BOD}}$ and $W D$. This similarity can be used to estimate the temporal dynamics of $T_{\text {mean }}$ and $T_{98}$ through ground-based air pressure measurements, the assessment of which would otherwise only be possible through more complex, tower-based wind speed measurements above the forest canopy.

Since the functional relationship between air pressure fluctuations measured on the ground and above-canopy wind speed is not due to a known local dependence, it is possible to calibrate the pressure fluctuations and wind-induced tree motion with wind speed measurements made outside of forests, e.g., in the networks of the national meteorological services. For example, the air pressure fluctuations measured in this study can be correlated ( $R=0.70$ ) with the nearest wind speed measurement made by the German Meteorological Service at $10 \mathrm{~m}$ a.g.1. in the city of Freiburg, $20 \mathrm{~km}$ northeast of the measurement site. Thus, we see potential that in the future, the available measuring stations located outside of forests can be used for an improved estimation of wind speed in forested areas.

\section{Conclusions}

The presented results show that ground-based measurements of air pressure fluctuations are suitable for estimating the temporal dynamics of mean and extreme tree response in a planted Scots pine forest. The significant advantages of the low-cost air pressure measurements are their ease of installation and the potential for deployment in large numbers over extensive areas. The results demonstrate that one air pressure measurement is sufficient to obtain spatially representative estimates of wind conditions over the forest in the presented measurement grid. This feature of the air pressure measurement can complement and potentially replace more complex tower-based wind measurements in remote forest areas with poorly developed infrastructure and research facilities. If a vertical profile of wind speed measurements is available, at least over a short period of time, then even a parameterization of the mean vertical wind speed profile could be achieved.

To evaluate the air pressure sensors' general suitability, a simplified set up is required to be tested in more complex terrain in future studies, e.g., at existing forest research sites with tall meteorological towers. The air pressure measurements could be used in combination with tree response sensors to capture better the small-scale variability of airflow, which to date remains very difficult to describe and quantify. The proposed approach to use low-cost, ground-based air pressure measurements for airflow approximation opens up opportunities to contribute to improved small-scale storm hazard assessment through the large-scale deployment of air pressure measurement networks located on the ground in forests. It may even be considered that a large-scale measurement network is used to monitor the adaptation of trees to the local wind climate. This could provide new insights into the interactions of wind-induced sway, tree acclimation, air pressure fluctuations, and canopy airflow. 
Author Contributions: Conceptualization, S.K., D.S.; methodology, S.K., M.M. (Martin Maier), B.G., D.S.; software, S.K., D.S.; validation, S.K., M.M. (Manuel Mohr), D.S.; formal analysis, S.K., D.S.; investigation, S.K., D.S.; resources, M.M. (Martin Maier), D.S.; data curation, S.K., D.S.; writingoriginal draft preparation, S.K.; writing-S.K., M.M. (Manuel Mohr), M.M. (Martin Maier), L.O., B.G., D.S.; visualization, D.S.; supervision, D.S.; project administration, S.K., D.S.; funding acquisition, M.M. (Martin Maier), D.S. All authors have read and agreed to the published version of the manuscript.

Funding: This research was funded by the German Research Foundation, grants SCHI 868/3-1, SCHI $868 / 5-1$.

Institutional Review Board Statement: Not applicable.

Informed Consent Statement: Not applicable.

Data Availability Statement: Data available on request.

Conflicts of Interest: The authors declare no conflict of interest.

\section{Nomenclature}

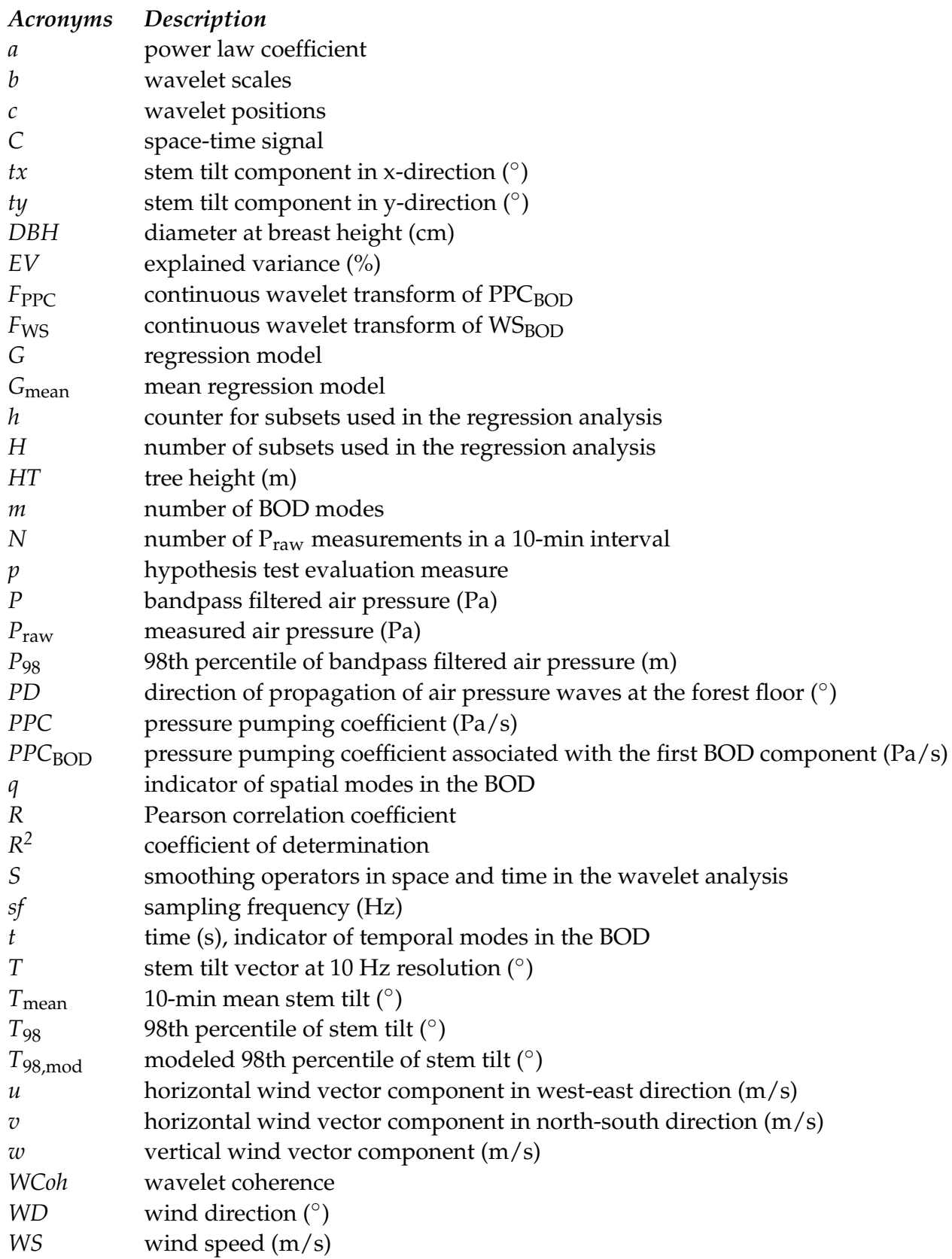




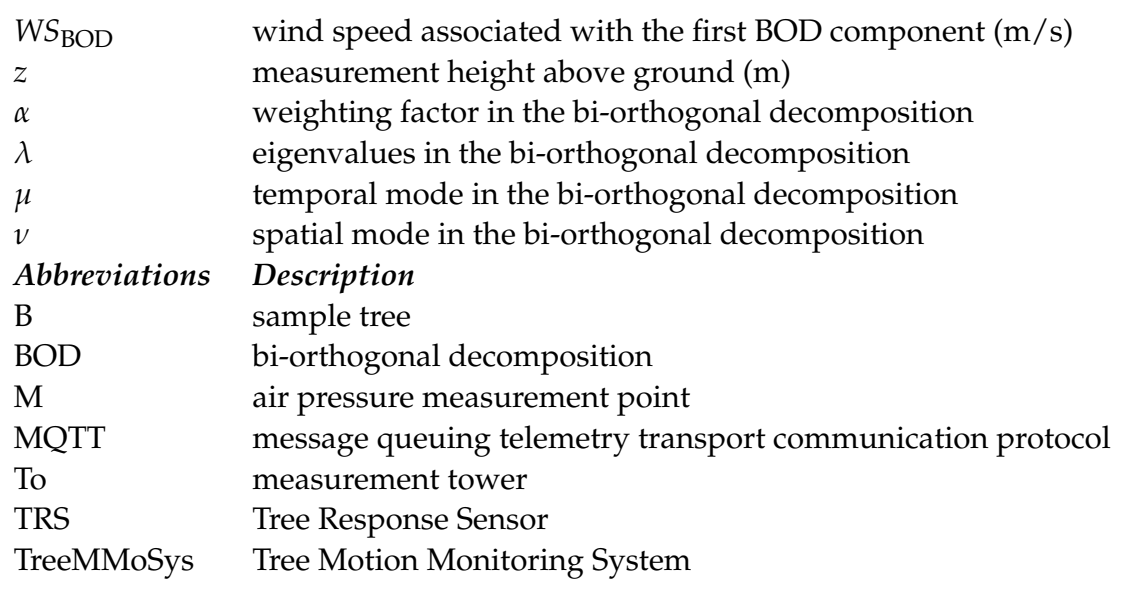

\section{References}

1. Gardiner, B.; Berry, P.; Moulia, B. Review: Wind impacts on plant growth, mechanics and damage. Plant Sci. 2016, 245, 94-118. [CrossRef] [PubMed]

2. Gardiner, B. Wind damage to forests and trees: A review with an emphasis on planted and managed forests. J. For. Res. 2021, 26, 248-266. [CrossRef]

3. Badel, E.; Ewers, F.W.; Cochard, H.; Telewski, F.W. Acclimation of mechanical and hydraulic functions in trees: Impact of the thigmomorphogenetic process. Front. Plant Sci. 2015, 6, 266. [CrossRef] [PubMed]

4. Niez, B.; Dlouha, J.; Moulia, B.; Badel, E. Water-stressed or not, the mechanical acclimation is a priority requirement for trees Trees 2018, 33, 279-291. [CrossRef]

5. Dèfossez, P.; Rajaonalison, F.; Bosc, A. How wind acclimation impacts Pinus pinaster growth in comparison to resource availability. Forestry 2021, 1-12. [CrossRef]

6. Telewski, F.W. Mechanosensing and Plant Growth Regulators Elicited During the Thigmomorphogenetic Response. Front. For. Glob. Chang. 2021, 3, 1-8. [CrossRef]

7. LWF (Bavarian State Institute of Forestry). Environmental Monitoring. Available online: https://www.lwf.bayern.de/bodenklima/umweltmonitoring/index.php (accessed on 26 November 2021).

8. WSL (Swiss Federal Institute for Forest, Snow and Landscape Research). Instrumented field sites and laboratories. Available online: https:/ / www.wsl.ch/en/about-wsl/instrumented-field-sites-and-laboratories.html (accessed on 26 November 2021).

9. ICOS (Integrated Carbon Observation System). Ecosystem stations. Available online: https://www.icos-cp.eu/observations/ ecosystem/stations (accessed on 26 November 2021).

10. ICP (International Co-operative Programme on Assessment and Monitoring of Air pollution Effects on Forests). Plots and data. Available online: http:/ /icp-forests.net/page/plots-data (accessed on 26 November 2021).

11. WMO (World Meteorological Organization). Guide to Instruments and Methods of Observation, Volume I - Measurement of Meteorological Variables. Available online: https://library.wmo.int/doc_num.php?explnum_id=10616 (accessed on 26 November 2021).

12. Mayer, H. Wind-induced tree sways. Trees 1987, 1, 195-206. [CrossRef]

13. Jackson, T.D.; Sethi, S.; Dellwik, E.; Angelou, N.; Bunce, A.; van Emmerik, T.; Duperat, M.; Ruel, J.-C.; Wellpott, A.; Van Bloem, S.; et al. The motion of trees in the wind: A data synthesis. Biogeosciences 2021, 18, 4059-4072. [CrossRef]

14. De Langre, E. Plant vibrations at all scales: A review. J. Exp. Bot. 2019, 70, 3521-3531. [CrossRef]

15. Meng, S.X.; Lieffers, V.J.; Reid, D.E.B.; Rudnicki, M.; Silins, U.; Jin, M. Reducing stem bending increases the height growth of tall pines. J. Exp. Bot. 2006, 57, 3175-3182. [CrossRef]

16. Nicoll, B.C.; Connolly, T.; Gardiner, B. Changes in Spruce Growth and Biomass Allocation Following Thinning and Guying Treatments. For. 2019, 10, 253. [CrossRef]

17. Wade, J.E.; Hewson, E.W. Trees as a Local Climatic Wind Indicator. J. Appl. Meteorol. 1979, 18, 1182-1187. [CrossRef]

18. Brüchert, F.; Gardiner, B. The effect of wind exposure on the tree aerial architecture and biomechanics of Sitka spruce (Picea sitchensis, Pinaceae). Am. J. Bot. 2006, 93, 1512-1521. [CrossRef] [PubMed]

19. Telewski, F. Structure and function of flexure wood in Abies fraseri. Tree Physiol. 1989, 5, 113-121. [CrossRef] [PubMed]

20. Secondary Xylem Biology. In Secondary Xylem Biology; Elsevier BV: Amsterdam, The Netherlands, 2015; pp. 73-91.

21. Schindler, D.; Kolbe, S. Assessment of the Response of a Scots Pine Tree to Effective Wind Loading. For. 2020, 11, 145. [CrossRef]

22. Schindler, D.; Mohr, M. Non-oscillatory response to wind loading dominates movement of Scots pine trees. Agric. For. Meteorol. 2018, 250-251, 209-216. [CrossRef]

23. Schindler, D.; Mohr, M. No resonant response of Scots pine trees to wind excitation. Agric. For. Meteorol. 2019, 265, 227-244. [CrossRef]

24. Stull, R.B. An Introduction to Boundary Layer Meteorology; Springer Science \& Business Media: Berlin, Germany, 1988. [CrossRef] 
25. Mohr, M.; Laemmel, T.; Maier, M.; Schindler, D. Analysis of Air Pressure Fluctuations and Topsoil Gas Concentrations within a Scots Pine Forest. Atmosphere 2016, 7, 125. [CrossRef]

26. Laemmel, T.; Mohr, M.; Longdoz, B.; Schack-Kirchner, H.; Lang, F.; Schindler, D.; Maier, M. From above the forest into the soil How wind affects soil gas transport through air pressure fluctuations. Agric. For. Meteorol. 2019, 265, 424-434. [CrossRef]

27. Shaw, R.H.; Paw, K.T.U.; Zhang, X.J.; Gao, W.; Hartog, G.D.; Neumann, H.H. Retrieval of turbulent pressure fluctuations at the ground surface beneath a forest. Boundary-Layer Meteorol. 1990, 50, 319-338. [CrossRef]

28. Shaw, R.H.; Zhang, X.J. Evidence of pressure-forced turbulent flow in a forest. Boundary-Layer Meteorol. 1992, 58, 273-288. [CrossRef]

29. Baldocchi, D.; Meyers, T.P. Turbulence structure in a deciduous forest. Boundary-Layer Meteorol. 1988, 43, 345-364. [CrossRef]

30. Raupach, M.R.; Finnigan, J.J.; Brunei, Y. Coherent eddies and turbulence in vegetation canopies: The mixing-layer analogy. Boundary-Layer Meteorol. 1996, 78, 351-382. [CrossRef]

31. Finnigan, J.J.; Shaw, R.H.; Patton, E.G. Turbulence structure above a vegetation canopy. J. Fluid Mech. 2009, 637, 387-424. [CrossRef]

32. Shaw, R.H.; U, K.T.P.; Gao, W. Detection of temperature ramps and flow structures at a deciduous forest site. Agric. For. Meteorol. 1989, 47, 123-138. [CrossRef]

33. Thomas, C.; Foken, T. Detection of long-term coherent exchange over spruce forest using wavelet analysis. Arch. Meteorol. Geophys. Bioclimatol. Ser. B 2005, 80, 91-104. [CrossRef]

34. Su, H.-B.; Shaw, R.H.; U, K.T.P. Two-Point Correlation Analysis Of Neutrally Stratified Flow Within And Above A Forest From Large-Eddy Simulation. Boundary-Layer Meteorol. 2000, 94, 423-460. [CrossRef]

35. Mohr, M.; Laemmel, T.; Maier, M.; Schindler, D. Spatial variability of wind-induced air pressure fluctuations responsible for pressure pumping. Tellus B: Chem. Phys. Meteorol. 2017, 69, 1361757. [CrossRef]

36. Sigmon, J.T.; Knoerr, K.R.; Shaughnessy, E.J. Microscale pressure fluctuations in a mature deciduous forest. Boundary-Layer Meteorol. 1983, 27, 345-358. [CrossRef]

37. Maier, M.; Schack-Kirchner, H.; Hildebrand, E.E.; Holst, J. Pore-space CO2 dynamics in a deep, well-aerated soil. Eur. J. Soil Sci. 2010, 61, 877-887. [CrossRef]

38. Massman, W.J.; Frank, J.M. Advective transport of CO2in permeable media induced by atmospheric pressure fluctuations: 2. Observational evidence under snowpacks. J. Geophys. Res. Space Phys. 2006, 111, 03005. [CrossRef]

39. Seok, B.; Helmig, D.; Williams, M.W.; Liptzin, D.; Chowanski, K.; Hueber, J. An automated system for continuous measurements of trace gas fluxes through snow: An evaluation of the gas diffusion method at a subalpine forest site, Niwot Ridge, Colorado. Biogeochem. 2009, 95, 95-113. [CrossRef]

40. Bowling, D.R.; Massman, W.J. Persistent wind-induced enhancement of diffusive CO2transport in a mountain forest snowpack. J. Geophys. Res. Space Phys. 2011, 116, 04006. [CrossRef]

41. Drake, S.A.; Selker, J.S.; Higgins, C.W. Wind enhances differential air advection in surface snow at sub-meter scales. Cryosphere 2017, 11, 2075-2087. [CrossRef]

42. Graham, L.; Risk, D. Explaining CO2 fluctuations observed in snowpacks. Biogeosciences 2018, 15, 847-859. [CrossRef]

43. Subke, J.-A.; Reichstein, M.; Tenhunen, J.D. Explaining temporal variation in soil CO2 efflux in a mature spruce forest in Southern Germany. Soil Biol. Biochem. 2003, 35, 1467-1483. [CrossRef]

44. EM (Environmental Meteorology, University of Freiburg, Germany). Hartheim Forest Research Site. Available online: https: / / www.meteo.uni-freiburg.de/en/infrastructure/hartheim-forest-research-site (accessed on 26 November 2021).

45. Mohr, M.; Schindler, D. Coherent Momentum Exchange above and within a Scots Pine Forest. Atmosphere 2016, 7, 61. [CrossRef]

46. Mohr, M.; Laemmel, T.; Maier, M.; Schindler, D. Inexpensive high-precision system for measuring air pressure fluctuations. Meteorol. Appl. 2020, 27, 1815. [CrossRef]

47. Nishiyama, R.T.; Bedard, A.J., Jr. A "Quad-Disc" static pressure probe for measurement in adverse atmospheres: With a comparative review of static pressure probe designs. Rev. Sci. Instruments 1991, 62, 2193-2204. [CrossRef]

48. Burns, S.P.; Frank, J.M.; Massman, W.J.; Patton, E.G.; Blanken, P.D. The effect of static pressure-wind covariance on vertical carbon dioxide exchange at a windy subalpine forest site. Agric. For. Meteorol. 2021, 306, 108402. [CrossRef]

49. Hale, S.E.; Gardiner, B.A.; Wellpott, A.; Nicoll, B.; Achim, A. Wind loading of trees: Influence of tree size and competition. Forstwiss. Centralblatt 2010, 131, 203-217. [CrossRef]

50. Jackson, T.; Shenkin, A.; Wellpott, A.; Calders, K.; Origo, N.; Disney, M.; Burt, A.; Raumonen, P.; Gardiner, B.; Herold, M.; et al. Finite element analysis of trees in the wind based on terrestrial laser scanning data. Agric. For. Meteorol. 2019, 265, 137-144. [CrossRef]

51. The Mathworks (The MathWorks Inc., Natick, Massachusetts). Matlab function findpeaks-Find local maxima. Available online: https://de.mathworks.com/help/signal/ref/findpeaks.html (accessed on 26 November 2021).

52. Kolbe, S.; Schindler, D. TreeMMoSys: A low cost sensor network to measure wind-induced tree response. HardwareX 2021, 9, e00180. [CrossRef]

53. Schindler, D.; Vogt, R.; Fugmann, H.; Rodríguez, M.; Schönborn, J.; Mayer, H. Vibration behavior of plantation-grown Scots pine trees in response to wind excitation. Agric. For. Meteorol. 2010, 150, 984-993. [CrossRef]

54. Aubry, N.; Guyonnet, R.; Lima, R. Spatiotemporal analysis of complex signals: Theory and applications. J. Stat. Phys. 1991, 64, 683-739. [CrossRef] 
55. Kaiser, H.F. The Application of Electronic Computers to Factor Analysis. Educ. Psychol. Meas. 1960, 20, 141-151. [CrossRef]

56. Gardiner, B.; Stacey, G.R.; Belcher, R.E.; Wood, C.J. Field and wind tunnel assessments of the implications of respacing and thinning for tree stability. For. Int. J. For. Res. 1997, 70, 233-252. [CrossRef]

57. Usbeck, T.; Wohlgemuth, T.; Pfister, C.; Volz, R.; Beniston, M.; Dobbertin, M. Wind speed measurements and forest damage in Canton Zurich (Central Europe) from 1891 to winter 2007. Int. J. Clim. 2010, 30, 347-358. [CrossRef]

58. Schindler, D.; Jung, C.; Buchholz, A. Using highly resolved maximum gust speed as predictor for forest storm damage caused by the high-impact winter storm Lothar in Southwest Germany. Atmospheric Sci. Lett. 2016, 17, 462-469. [CrossRef]

59. Gromke, C.; Ruck, B. On Wind Forces in the Forest-Edge Region During Extreme-Gust Passages and Their Implications for Damage Patterns. Boundary-Layer Meteorol. 2018, 168, 269-288. [CrossRef]

60. Torrence, C.; Webster, P.J. Interdecadal changes in the ENSO-monsoon system. J. Clim. 1999, 12, 2679-2690. [CrossRef]

61. Breiman, L. Bagging predictors. Mach. Learn. 1996, 24, 123-140. [CrossRef]

62. Pyles, R. Directional wind shear within an old-growth temperate rainforest: Observations and model results. Agric. For. Meteorol. 2004, 125, 19-31. [CrossRef]

63. Lee, X.; Shaw, R.H.; Black, T. Modelling the effect of mean pressure gradient on the mean flow within forests. Agric. For. Meteorol. 1994, 68, 201-212. [CrossRef]

64. Su, H.-B.; Schmid, H.; Vogel, C.; Curtis, P. Effects of canopy morphology and thermal stability on mean flow and turbulence statistics observed inside a mixed hardwood forest. Agric. For. Meteorol. 2008, 148, 862-882. [CrossRef]

65. Takle, E.S.; Massman, W.J.; Brandle, J.R.; Schmidt, R.; Zhou, X.; Litvina, I.V.; Garcia, R.; Doyle, G.; Rice, C.W. Influence of high-frequency ambient pressure pumping on carbon dioxide efflux from soil. Agric. For. Meteorol. 2004, 124, 193-206. [CrossRef] 